\title{
Amyloid- $\beta$ Oligomers Regulate ADAM10 Synaptic Localization Through Aberrant Plasticity Phenomena
}

\author{
Elena Marcello ${ }^{1}$ (D) - Stefano Musardo ${ }^{1,2} \cdot$ Lina Vandermeulen $^{1} \cdot$ Silvia Pelucchi ${ }^{1,3} \cdot$ Fabrizio Gardoni $^{1}$ • Nadia Santo ${ }^{4}$. \\ Flavia Antonucci ${ }^{5} \cdot$ Monica Di Luca $^{1}$
}

Received: 21 January 2019 / Accepted: 21 March 2019 / Published online: 13 April 2019

(C) The Author(s) 2019

\begin{abstract}
A disintegrin and metalloproteinase 10 (ADAM10) is a synaptic enzyme that has been previously shown to limit amyloid- $\beta_{1-42}$ $\left(A \beta_{1-42}\right)$ peptide formation in Alzheimer's disease (AD). Furthermore, ADAM10 participates to spine shaping through the cleavage of adhesion molecules and its activity is under the control of synaptic plasticity events. In particular, long-term depression (LTD) promotes ADAM10 synaptic localization triggering its forward trafficking to the synapse, while long-term potentiation elicits ADAM10 internalization. Here, we show that a short-term in vitro exposure to $A \beta_{1-42}$ oligomers, at a concentration capable of inducing synaptic depression and spine loss, triggers an increase in ADAM10 synaptic localization in hippocampal neuronal cultures. However, the $A \beta_{1-42}$ oligomers-induced synaptic depression does not foster ADAM10 delivery to the synapse, as the physiological LTD, but impairs ADAM10 endocytosis. Moreover, $A \beta_{1-42}$ oligomers-induced inhibition of ADAM10 internalization requires neuronal activity and the activation of the NMDA receptors. These data suggest that, at the synaptic level, $A \beta_{1-42}$ oligomers trigger an aberrant plasticity mechanism according to which $A \beta_{1-42}$ oligomers can downregulate $A \beta$ generation through the modulation of ADAM10 synaptic availability. Moreover, the increased activity of ADAM10 towards its synaptic substrates could also affect the structural plasticity phenomena. Overall, these data shed new lights on the strict and complex relationship existing between synaptic activity and the primary mechanisms of AD pathogenesis.
\end{abstract}

Keywords ADAM10 $\cdot$ Alzheimer disease $\cdot$ Amyloid- $\beta \cdot$ Synaptic plasticity

Elena Marcello and Stefano Musardo contributed equally to this work and are listed alphabetically

Electronic supplementary material The online version of this article (https://doi.org/10.1007/s12035-019-1583-5) contains supplementary material, which is available to authorized users.

Elena Marcello

elena.marcello@unimi.it

Monica Di Luca

monica.diluca@unimi.it

1 Department of Pharmacological and Biomolecular Sciences, Università degli Studi di Milano, Via Balzaretti 9, 20133 Milan, Italy

2 Present address: Department of Basic Neuroscience, University of Geneva, Rue Michel-Servet 1, 1206 Geneva, Switzerland

3 Department of Neurosciences, Psychology, Drug Research, and Child Health, University of Florence, Florence, Italy

4 Department of Life Sciences, Università degli Studi di Milano, Milan, Italy

5 Department of Biotechnology and Translational Medicine, Università degli Studi di Milano, Milan, Italy

\section{Abbreviations}

$\mathrm{AD}$

ADAM10

AMPA receptors

$\mathrm{A} \beta_{1-42}$

APP

$\mathrm{Ab}$

BSA

CTRL

DIV

LTD

LTP

mEPSCs

NMDA receptors

oA $\beta_{1-42}$

PBS

TEM

TIF

TTX
Alzheimer's disease

A disintegrin and metalloproteinase 10

$\alpha$-amino-3-hydroxy-5-methy

1-4-isoxazolepropionic acid receptor

amyloid- $\beta_{1-42}$

amyloid- $\beta$ precursor protein

antibody

bovine serum albumin

non-treated cultures

days in vitro

long-term depression

long-term potentiation

excitatory post-synaptic

current in miniature

N-methyl-D-aspartate (NMDA) receptors

oligomers of $A \beta_{1-42}$

phosphate buffered saline

transmission electron microscopy

Triton-insoluble fraction

tetrodotoxin 


\section{Background}

Disentangling the initial steps of Alzheimer's disease (AD) pathogenesis from full-blown pathology at a molecular and cellular level remains a key step to fully understand disease onset and progression. In this frame, it has been shown that synapse dysfunction and spine loss represent an early event of the disease rather than just a consequence of cell death [1]. Further, the synapses have been shown to be the main target of the amyloid- $\beta_{1-42}\left(A \beta_{1-42}\right)$ peptide, whose deposition is one of the main hallmarks of $\mathrm{AD}[2,3]$.

The $\mathrm{A} \beta_{1-42}$ peptide derives from a transmembrane protein, named amyloid- $\beta$ precursor protein (APP), that is mainly localized in the pre-synaptic active zone and in the post-synaptic compartment in the hippocampus and in the cortex [4].

The concerted action of the $\beta$-secretase BACE- 1 and the $\gamma$ secretase towards APP generates $A \beta_{1-42}$ [5]. Being APP cleavage mutually exclusive, in neuronal cells, A disintegrin and metalloproteinase 10 (ADAM10) cleaves APP within the $\mathrm{A} \beta_{1-42}$ domain, thus generating the neuroprotective sAPP $\alpha$ and precluding the formation of the $\mathrm{A} \beta_{1-42}$ peptide $[6,7]$.

The $A \beta_{1-42}$ homeostasis is regulated by synapse activation: increased activity enhances secretion of $A \beta_{1-42}$, while reduced activity inhibits it $[8,9]$. Coherently, also ADAM10 synaptic levels and activity towards APP are under the control of activitydependent synaptic plasticity [10]. Long-term depression (LTD) boosts ADAM10 membrane insertion by fostering its SAP97mediated forward trafficking to post-synaptic membrane, whereas long-term potentiation (LTP) reduces the enzyme membrane levels by inducing AP2-dependent endocytosis [10].

On the other hand, $A \beta_{1-42}$ can be considered a regulator of neuronal activity [8] since once released, it affects in turn synaptic transmission and plasticity. In particular, pathological $A \beta_{1-42}$ levels giving rise to the formation of $A \beta_{1-42}$ oligomers (oA $\beta_{1-}$ 42) may indirectly cause a partial block of N-methyl-D-aspartate (NMDA)-type glutamate receptors and shift the activation of NMDA receptors-dependent signaling cascades towards pathways involved in the induction of LTD and synaptic loss [11-13].

Here, we hypothesize that the $\mathrm{oA} \beta_{1-42}$-induced plasticity pathways have a feedback effect on ADAM10 synaptic localization. We show that short-term exposure to $\mathrm{oA} \beta_{1-42}$ reduces ADAM10 endocytosis, thus leading to an increase in ADAM10 synaptic localization. This effect is mediated by activation of synaptic NMDA receptors containing the GluN2A subunit.

\section{Results}

\section{Characterization of $\mathrm{OA} \boldsymbol{\beta}_{1-42}$ Effect on the Synapse}

In order to set up a reliable in vitro system to analyze the effect of $\mathrm{oA} \beta_{1-42}$ on ADAM10 synaptic localization, we performed a complete characterization of our experimental conditions.
First, $\mathrm{oA} \beta_{1-42}$ preparation was monitored and controlled by different means. As a negative control, we used a peptide with the reverse sequence of $A \beta\left(A \beta_{42-1}\right)$. Coomassie staining and Western Blot analysis with an antibody detecting the $N$-terminus of $A \beta$ (6E10 antibody) indicated that our $\mathrm{oA} \beta_{1-42}$ preparation resulted in a spectrum of oligomeric $A \beta$ species, from 4 up to $16 \mathrm{kDa}$ (Fig. 1a). Transmission electron microscopy (TEM) analysis of $\mathrm{oA} \beta_{1-42}$ confirmed the presence of globular, oligomeric structures, while no fibrillar or protofibrillar species were observed (Fig. 1b). $A \beta_{42-1}$ preparation is mainly constituted of monomers and of aggregated species. Western Blot analysis performed with $6 \mathrm{E} 10$ antibody showed no signal in $A \beta_{42-1}$ samples, as expected (Fig. 1a).

Consistent with previous studies $[14,15]$, we found that $\mathrm{oA} \beta_{1-42}$ species at a concentration of $500 \mathrm{nM}$ applied to hippocampal neurons for 24 hours (h) resulted in a significant reduction in spine density as compared to non-treated cultures (CTRL) or to cells exposed to $A \beta_{42-1}$ (Fig. 1c). Moreover, such concentration of $\mathrm{oA} \beta_{1-42}$ did not increase the mortality of the cells after $24 \mathrm{~h}$ of treatment, different from higher concentrations as $1 \mu \mathrm{M}, 5 \mu \mathrm{M}$, and $10 \mu \mathrm{M}$ (Fig. 1d).

$\mathrm{oA} \beta_{1-42}$ species have been shown to facilitate synaptic depression of neurons in acute slices $[13,16]$. Accordingly, hippocampal cultures exposed to $\mathrm{oA} \beta_{1-42}$ for $30 \mathrm{~min}$ displayed a global synaptic depression as indicated by electrophysiological recordings of excitatory post-synaptic current in miniature (mEPSCs) (Fig. 1e) as well as upon the delivery of the classical LTD protocol $(20 \mu \mathrm{M}$ NMDA and $20 \mu \mathrm{M}$ glycine for $3 \mathrm{~min}$, chemical LTD; Fig. 1e; [17, 18]). Moreover, we used a biochemical approach and we purified the Triton-insoluble fraction (TIF) that is enriched in postsynaptic proteins. As shown in Fig. 1f, the treatment with $\mathrm{oA} \beta_{1-42}(500 \mathrm{nM}, 30 \mathrm{~min}$ ) induced a significant dephosphorylation of serine 845 of the GluA1 subunit of $\alpha$-amino-3-hydroxy-5-methyl-4-isoxazolepropionic acid (AMPA) receptors, without any significant change in GluA1 synaptic levels, confirming that this concentration elicits synaptic depression [19]. No changes in the total and synaptic levels of NMDA receptor subunits and in PSD-95 were observed (Fig. 1f; Suppl. Fig. 1A, B).

These results suggest that our $\mathrm{OA} \beta_{1-42}$ preparation triggers a synaptic depression affecting specifically AMPA mediated conductance.

\section{oA $\beta_{1-42}$ Promote ADAM10 Synaptic Localization Impairing Its Endocytosis}

Given that ADAM10 synaptic localization is regulated by synaptic plasticity [10], can oA $\beta_{1-42}$ modify ADAM10 synaptic levels? To address this issue, we exposed hippocampal neuronal cultures to $\mathrm{oA} \beta_{1-42}(500 \mathrm{nM}, 30 \mathrm{~min})$. As shown in Fig. 2a, bath application of $o A \beta_{1-42}$ significantly increases the co-localization of ADAM10 with a post-synaptic marker, as 


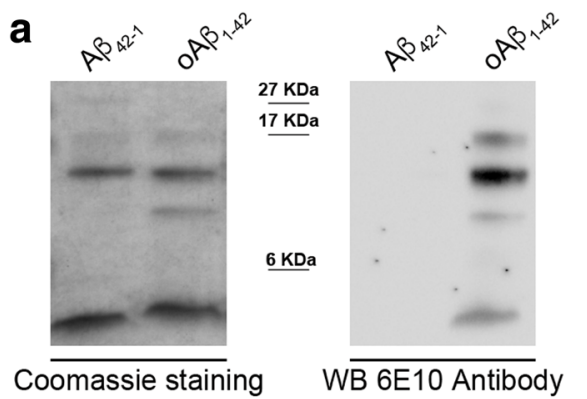

b

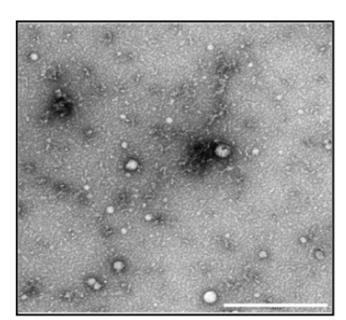

C

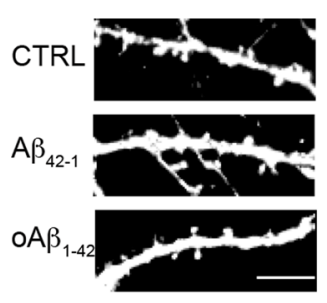

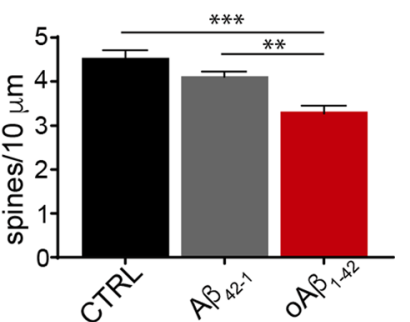

d

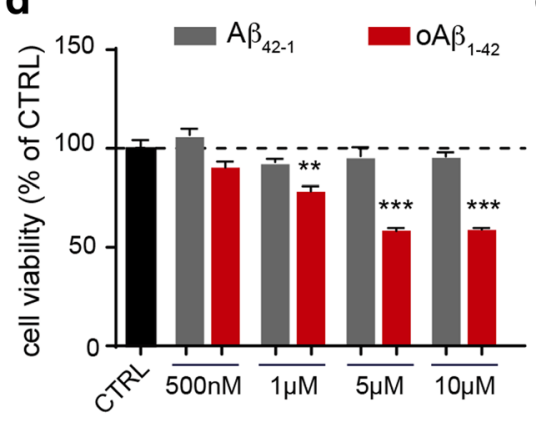

e

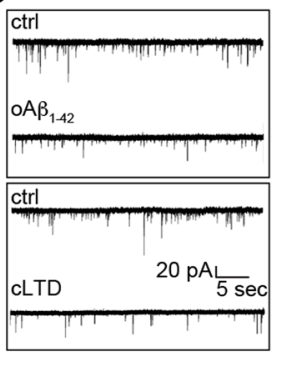

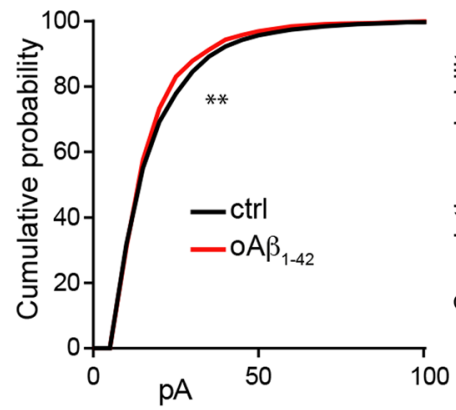

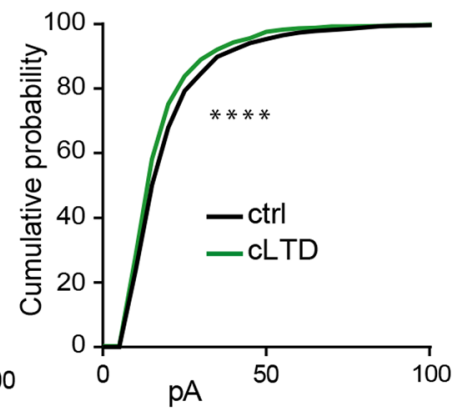

$\mathbf{f}$

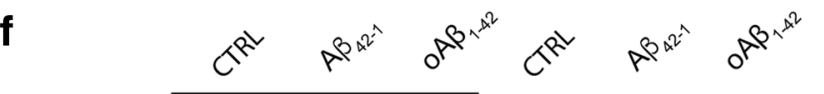

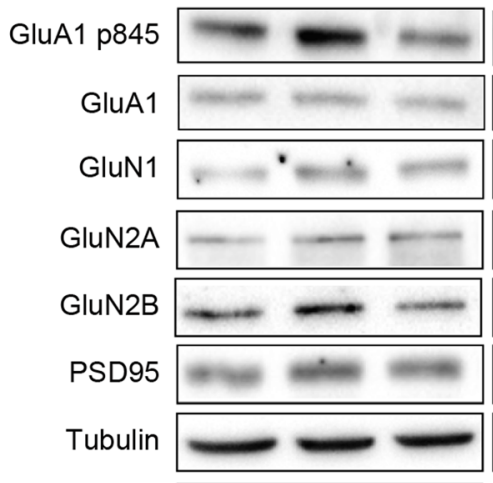

Homo
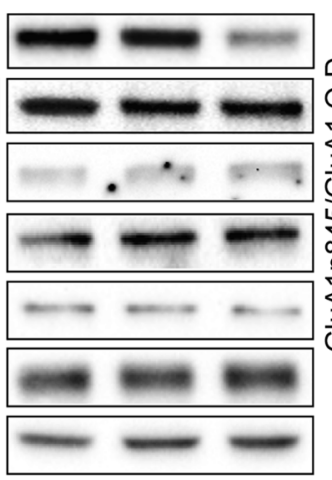

TIF

Fig. $1 \mathrm{~A} \beta$ oligomers characterization and effects on the synapses. a A representative Coomassie-stained polyacrylamide gel and Western blot analysis of $A \beta_{42-1}$ and $\mathrm{oA} \beta_{1-42}$. The image shows the presence of oligomers formation for $A \beta_{1-42}$ and monomer and aggregated forms for $\mathrm{A} \beta_{42-1}$. b TEM revealed globular but not fibrillar structures for oA $\beta_{1-}$ 42 preparation, scale bar $500 \mathrm{~nm}$. c Representative confocal images of GFP-transfected primary hippocampal neurons. The analysis shows that $\mathrm{oA} \beta_{1-42}(500 \mathrm{nM}, 24 \mathrm{~h})$ reduces spine density (CTRL $4.58 \pm 0.18 ; \mathrm{A} \beta_{42}$ $14.15 \pm 0.12$; oA $\beta_{1-42} 3.36 \pm 0.18$; ** $p<0.01$, *** $p<0.001$; one-way ANOVA, $n=34-45)$. Scale bar $5 \mu \mathrm{m}$. d MTT test shows that exposure to $\mathrm{oA} \beta_{1-42}$ for $24 \mathrm{~h}$ induces cell death starting from a concentration of $1 \mu \mathrm{M}\left(* * p<0.01, * * * p<0.001\right.$ one-way ANOVA, oA $\beta_{1-42}$ vs CTRL, $n=4)$. e Representative traces of mEPSCs collected in hippocampal neurons before and after $\mathrm{o} A \beta_{1-42}$ exposure (upper panel) and before and after chemical LTD (cLTD, lower panel). At least 21 neurons before and after

PSD-95, along dendrites when compared to untreated or $\mathrm{A} \beta_{42-1}$-treated cells.

To further confirm these results by a biochemical approach, we purified the TIF. ADAM10 levels were significantly increased in the TIF upon $\mathrm{oA} \beta_{1-42}$ treatment (Fig. 2b), indicating that $\mathrm{oA} \beta_{1-42}$
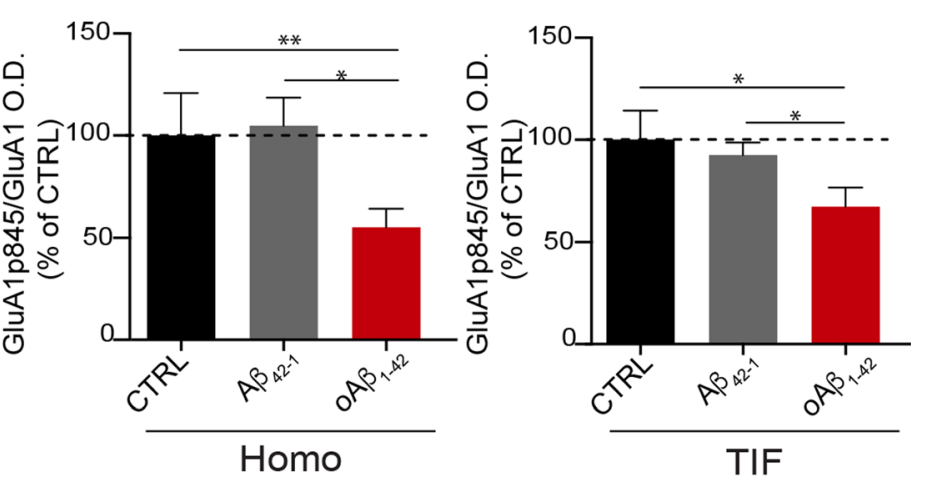

each treatment (oA $\beta_{1-42}$ or cLTD) have been analyzed and the related analysis of mEPSC amplitudes, here shown as cumulative probability, includes these $n$ of excitatory events: 1550 (before oA $\beta_{1-42}$, black line) vs 970 (after oA $\beta_{1-42}$, red line), CTRL vs oA $\beta_{1-42} p=0.0075 ; 2100$ (before cLTD, black line) vs 1970 (after cLTD, green line), CTRL vs cLTD $p<0.0001$. f Western blot analysis of synaptic protein levels in total homogenate $(\mathrm{HOMO})$ and synaptic fraction (TIF) upon oA $\beta_{1-42}$ treatment $(500 \mathrm{nM}, 30 \mathrm{~min})$. The quantification shows that $\mathrm{oA} \beta_{1-42}$ incubation for $30 \mathrm{~min}$ induces a decrease of GluA1 phosphorylation at 845 residue (GluA1p845/GluA1, HOMO: CTRL $100 \pm 20.76 \%, \mathrm{~A} \beta_{42-1}$ $104.80 \pm 13.77 \%, \mathrm{oA} \beta_{1-42} 55.22 \pm 9.05 \%$; TIF: CTRL $100 \pm 14.13 \%$, $\mathrm{A} \beta_{42-1} 92.40 \pm 6.21 \%, \mathrm{oA} \beta_{1-42} 67.36 \pm 9.30 \%, * p<0.05, * * p<0.001$, one-way ANOVA, $n=7-11)$. oA $\beta_{1-42}$ exposure does not induce significant changes of GluA1, NMDA receptors subunits (GluN1, GluN2A, GluN2B), and PSD-95 expression and synaptic localization

promote ADAM10 synaptic localization. We have previously shown that LTD induction fosters the SAP97-mediated ADAM10 trafficking to the synapse [10]. However, no alterations of SAP97 synaptic localization were detected upon oA $\beta_{1-42}$ treatment (Fig. 2b; Suppl. Fig. 2A). In addition, no modifications of the 
a
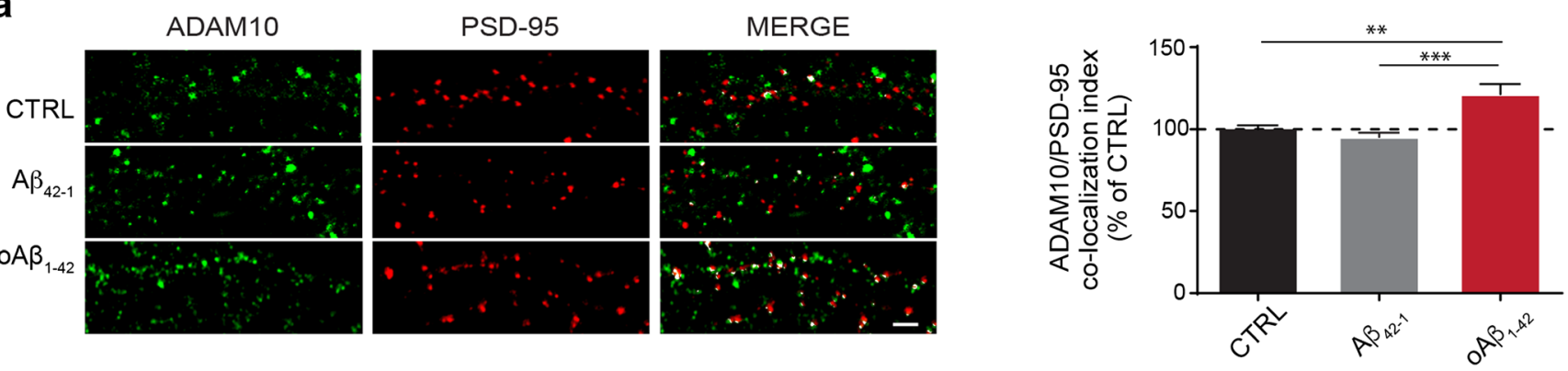

b
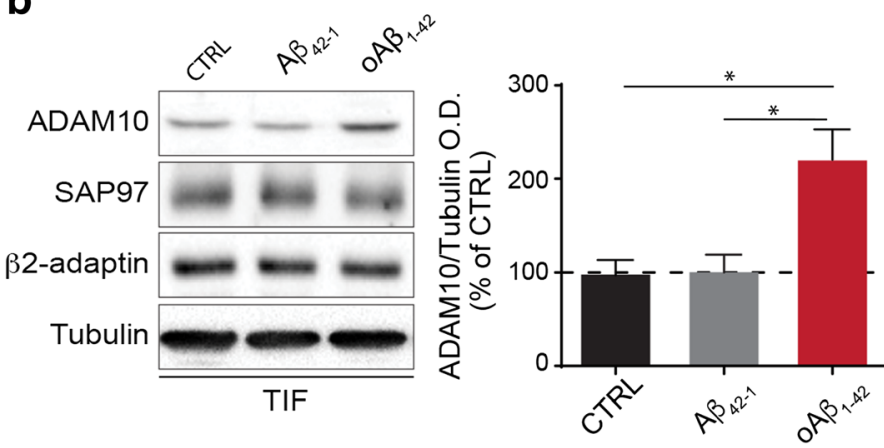

C

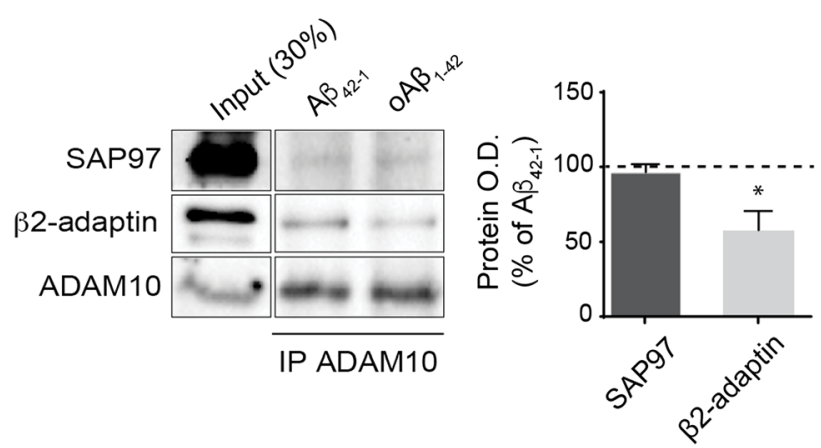

Fig. $2 \mathrm{oA} \beta_{1-42}$ treatment increases ADAM10 synaptic localization, impairing its endocytosis. a Confocal images of primary hippocampal neurons stained with PSD-95 (red) and ADAM10 (green). Cells were untreated (CTRL) or incubated for $30 \mathrm{~min}$ with either $\mathrm{oA} \beta_{1-42}$ or $\mathrm{A} \beta_{42-1}(500 \mathrm{nM})$. The challenge with oA $\beta_{1-42}$ increases the ADAM10/ PSD-95 co-localization index (CTRL $100 \pm 2.48 \%, A \beta_{42-1} 95.59 \pm$ $2.69 \%, \mathrm{oA} \beta_{1-42} 123.1 \pm 5.86 \% ; * p<0.05, * * p<0.01$ Kruskall-Wallis one-way analysis on variance, $n=30$ ). Representative images of ADAM10/PSD-95 co-localization (white) are shown on the right, scale bar $5 \mu \mathrm{m}$. b Representative images of western blot analysis of ADAM10

synaptic levels of $\beta 2$-adaptin, one of the subunits of the AP2 complex responsible for ADAM10 endocytosis [10], were observed (Fig. 2b; Suppl. Fig. 2B).

To determine the cellular mechanism underlying oA $\beta_{1-42}$-induced increase in ADAM10 synaptic localization, we analyzed the association of ADAM10 to SAP97 and AP2 complex. As shown in Fig. 2c, the $\mathrm{oA} \beta_{1-42}$ treatment does not alter the interaction with SAP97, while significantly decreases the interaction with $\beta 2$ adaptin, one of the subunits of AP2 complex. These results demonstrate that acute exposure to oA $\beta_{1-42}$ affects ADAM10 synaptic localization because of a decrease of endocytosis rather than to an increase of forward trafficking.

\section{oA $\beta_{1-42}$-Triggered ADAM10 Increased Synaptic Localization Is Mediated by the Activation of Synaptic GluN2A-Containing NMDARs}

To identify which of the cellular pathways triggered by oA $\beta_{1-42}$ is responsible for the increase in ADAM10 synaptic localization, we analyzed the effect of the blockade of different events. First, we took advantage of the action potential blocker tetrodotoxin (TTX) (500 nM), and we observed that TTX pre-incubation prevents the in the TIF of primary hippocampal neurons. The quantitative analysis shows that $\mathrm{oA} \beta_{1-42}$ increase ADAM10 synaptic localization (CTRL $100 \pm 16.55 \%, \mathrm{~A} \beta_{42-1} 102.7 \pm 18.9 \%$, oA $\beta_{1-42} 222 \pm 32.46 \%$; ${ }^{*} p<0.05$ one-way ANOVA, $n=3$ ). c Representative images of coimmunoprecipitation between ADAM10 and either SAP97 or $\beta 2$ adaptin. The quantitative analysis shows that $\mathrm{oA} \beta_{1-42}$ treatment reduces the interaction with $\beta 2$-adaptin without affecting the interaction with SAP97 (SAP97 96.95 $\pm 5.26 \%$, $\beta 2$-adaptin $57.39 \pm 17.81 \%, * p<0.05 t$ test $\mathrm{oA} \beta_{1-42}$ vs $\mathrm{A} \beta_{42-1}, n=3$ )

$\mathrm{oA} \beta_{1-42}$-induced increase of ADAM10 in the TIF (Fig. 3a), indicating the involvement of neuronal synaptic activity.

In the adult forebrain, synaptic NMDA receptors are predominantly di-heteromeric GluN1/GluN2A and tri-heteromeric GluN1/GluN2A/GluN2B receptors [20, 21]. In light of this observation and considering the key role of GluN2A-containing NMDA receptors in plasticity phenomena $[22,23]$, we examined the effect of NVP-AAM077, a GluN2A-preferring antagonist [24]. The analysis of ADAM10 levels in the TIF shows that the presence of NVP-AAM077 fully prevents the increased localization of ADAM10 in the synapses induced by oA $\beta_{1-42}$ (Fig. 3b). Notably, the presence of ifenprodil, an antagonist of GluN2Bcontaining NMDA receptors, does not affect the oA $\beta_{1-42}$-triggered increase in ADAM10 synaptic levels, thus indicating the specific involvement of GluN2A-containing NMDA receptors (Suppl. Fig. 3).

\section{Discussion}

In this study, we provide evidence for aberrant plasticity phenomena by which oA $\beta_{1-42}$ control synaptic function and the 

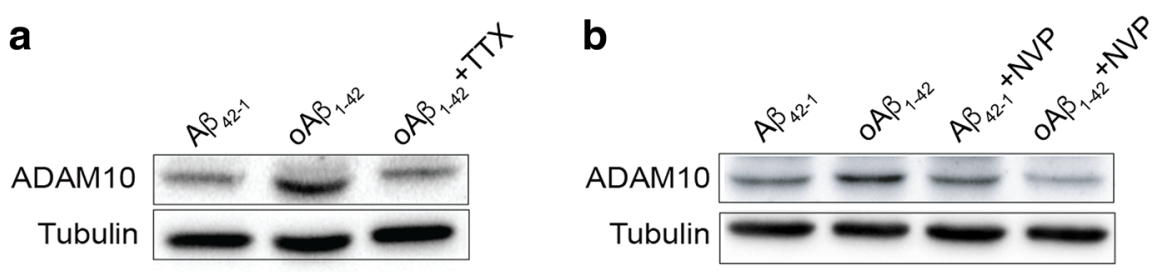

C

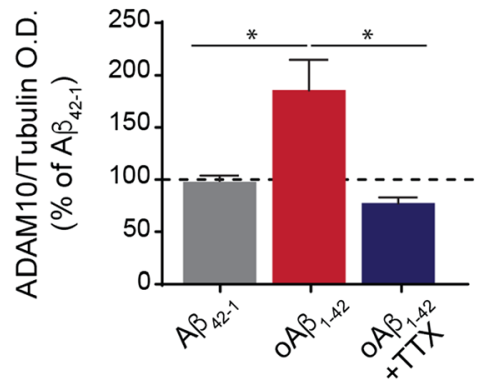

Fig. 3 oA $\beta_{1-42}$-triggered ADAM10 increase in synaptic localization requires neuronal activity and the activation of GluN2A-containing NMDA receptors. a Representative images of Western Blot analysis of ADAM10 levels in the TIF of primary hippocampal neurons treated with TTX for 15 min and then challenged with $A \beta_{42-1}$ or $\mathrm{oA} \beta_{1-42}$. The quantitative analysis shows that TTX prevents the $\mathrm{OA} \beta_{1-42}$-induced increase in ADAM10 synaptic localization $\left(\mathrm{A} \beta_{42-1} 100 \pm 5.80 \%\right.$, oA $\beta_{1-42}$ $187.80 \pm 29.51 \%$, oA $\beta_{1-42}+$ TTX $79.57 \pm 5.84 \%, * p<0.05$, one-way

generation of $A \beta_{1-42}$ itself. Primary hippocampal cultures were treated with a preparation of $\mathrm{oA} \beta_{1-42}$ able to induce synaptic depression in $30 \mathrm{~min}$ and spine loss in $24 \mathrm{~h}$, in the absence of cell death. In these experimental conditions, oA $\beta_{1-}$ 42 short-term exposure results in an increase in ADAM10 synaptic availability. Although it has been shown that LTD fosters SAP97-mediated ADAM10 delivery to the postsynaptic compartment [10], oA $\beta_{1-42}$ treatment leads to a decrease in the association between ADAM10 and AP2 complex, which is responsible for the endocytosis of the enzyme, without affecting the binding to SAP97 (Fig. 3c). Therefore, the increase in ADAM10 synaptic localization is due to the impairment of its endocytosis rather than to a stimulation of its forward trafficking, suggesting that the molecular pathways underlying physiological LTD and regulating ADAM10 are

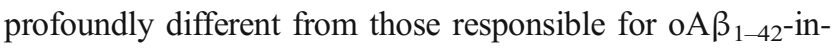
duced depression.

Considering that several studies demonstrated that oA $\beta_{1-42}$ inhibit the maintenance of hippocampal LTP $[8,25,26]$ and that ADAM10 endocytosis is regulated by LTP, we can also hypothesize that the oA $\beta_{1-42}$-induced impairment in ADAM10 endocytosis is in line with a disorder in mechanism of LTP. Thus, overall our data indicate that $\mathrm{oA} \beta_{1-42}$ triggers aberrant plasticity phenomena.

We provide also a mechanistic inside for this aberrant plasticity of $\mathrm{oA} \beta_{1-42}$ action. $\mathrm{oA} \beta_{1-42}$ engage a pathway that requires neuronal activity and the activation of the GluN2A-containing NMDA receptors. Even if several studies reported the role of the extra-synaptic GluN2B-containing NMDA receptors [27-29], our data highlight that acute exposure to $\mathrm{oA} \beta_{1-42}$ triggers a synaptic event that involves GluN2A-containing NMDA receptors. Indeed, the presence of an inhibitor of GluN2B-containing NMDA receptors does not prevent the $\mathrm{oA} \beta_{1-42}$-induced increase in ADAM10 synaptic localization.

Taken together, these data suggest that a short-term exposure to $\mathrm{oA} \beta_{1-42}$ engages a negative feedback mechanism according to which $\mathrm{oA} \beta_{1-42}$ can downregulate $A \beta$ generation through the modulation of ADAM10 synaptic availability. Moreover, the increased activity of ADAM10 towards its synaptic substrates could tune synaptic transmission and structural plasticity. It has been shown that the $\mathrm{SAPP} \alpha$, which is released after ADAM10 cleavage of APP, is able to acutely modulate synaptic strength when applied in vitro [30]. Furthermore, ADAM10-mediated shedding of N-cadherin controls spine shaping and AMPA receptors function [31].

Overall, here, we show that $\mathrm{o} A \beta_{1-42}$ can trigger aberrant plasticity pathways and, thereby, affect synaptic plasticity. Since the synapses are considered to be an early site of pathology in $\mathrm{AD}[32]$ and loss of synapses is the best pathologic correlate of cognitive impairment in AD patients [33], understanding the molecular underpinnings leading to synaptic dysfunction will aid in the development of tailored synapsetargeted therapies for AD.

\section{Methods}

\section{Amyloid Oligomers Preparation}

$A \beta_{1-42}$ and $A \beta_{42-1}$ peptides were purchased from Bachem (Bubendorf, Switzerland) and oligomers were prepared 
according to [34]. The lyophilized peptides were dissolved in 1,1,1,3,3,3-hexafluoro-2-propanol (HFIP; Sigma, St. Louis, MO, USA) and aliquoted before removing HFIP. oA $\beta_{1-42}$ were obtained by incubating at $4{ }^{\circ} \mathrm{C}$ for $24 \mathrm{~h}$ in Neurobasal medium without Phenol red. The quality of the oligomer preparation was controlled separating the protein onto a 13\% TrisTricine gels and performing Coomassie staining and western blots against the amyloid- $\beta$ peptide (6E10; Covance, CA, USA). To analyze the presence of oligomeric and fibrillar forms, TEM experiments were performed by applying $5 \mu \mathrm{l}$ of protein suspension to a glow-discharge coated carbon grid (Cu 300 mesh, Electron Microscopy Sciences, PA, USA) for $1 \mathrm{~min}$ and then negatively stained with $2 \%$ Uranyl acetate. Sample was observed at an EFTEM Leo912ab (Zeiss, Germany) operating at $100 \mathrm{kV}$ and digital images were acquired by a CCD camera $1 \mathrm{kx} 1 \mathrm{k}$ (Proscan, Germany) and iTEM software (Olympus, Germany).

\section{Neuronal Cultures Preparation, Transfection, and Treatments}

Primary hippocampal neurons cultures were prepared from embryonic day 18-19 rat hippocampi as previously described [35]. The Institutional Animal Care and Use Committee of University of Milan and the Italian Ministry of Health (\#326/2015) approved all the experiments involving primary neuronal cultures preparation.

Neurons were transfected with eGFP plasmid using the calcium phosphate precipitation method at 10 days in vitro $(D I V)$ for spines density analysis. All the treatments were performed at DIV14 using the following reagents concentrations: either $\mathrm{oA} \beta_{1-42}$ or $\mathrm{A} \beta_{42-1} 500 \mathrm{nM}$ (30 min), NVP-AAM077 (GluN2A-containing NMDA receptor antagonist, TOCRIS, Bristol, UK) $50 \mathrm{nM}$ (pre-incubation of $15 \mathrm{~min}$ ), TTX (Tetrodotoxin, TOCRIS) $500 \mathrm{nM}$ (pre-incubation of $15 \mathrm{~min}$ ), and ifenprodil (GluN2B-containing NMDA receptor antagonist, TOCRIS) $3 \mu \mathrm{M}$ (pre-incubation of $5 \mathrm{~min}$ ). Neuronal cultures were treated with either $\mathrm{o} A \beta_{1-42}$ or $A \beta_{42-}$ 1 at different concentrations $(500 \mathrm{nM}, 1 \mu \mathrm{M}, 5 \mu \mathrm{M}$, and $10 \mu \mathrm{M}$ ) and, after $24 \mathrm{~h}$, the MTT test was performed according to [36] to evaluate the cells viability.

\section{Synaptic Fraction Purification, Western Blot, and Co-immunoprecipitation Analysis}

After treatment, samples were processed for the purification of the Triton-insoluble fraction (TIF), a fraction enriched in postsynaptic density proteins [35]. After quantification, total homogenate and TIF proteins were resolved with SDS-PAGE method; co-immunoprecipitation experiments were performed as described in $[10,35]$.

\section{Antibodies}

The following antibodies $(\mathrm{Ab})$ were used: ADAM10 purchased from Abcam ab39153 (Cambridge, UK), SAP97 from Stressgen ADI-VAM-PS005-D (San Diego, CA, USA), $\beta 2$ Adaptin from BD Bioscience 610382 (NJ, USA), Tubulin T9026 and GluN2A M264 from Sigma-Aldrich, GluA1 75327, PSD-95 75-028, GluN2B 75-097, and GFP 75-132 from Neuromab (Davis, CA, USA), GluA1-p845 04-1073 and 6E10 SIG39320-200 (Covance) from Millipore (Billenca, MA, USA), and GluN1 320500 from Thermo Fisher (Waltham, MA, USA). Peroxidase-conjugated secondary Abs were purchased from Bio-Rad (Hercules, CA, USA). AlexaFluor secondary Abs were purchased from Thermo Fisher.

\section{Immunocytochemistry and Confocal Microscope Acquisition}

For ADAM10/PSD-95 co-localization and spine morphology studies, treated hippocampal neurons were fixed $7 \mathrm{~min}$ in $4 \%$ paraformaldehyde plus $4 \%$ sucrose in phosphate buffered saline (PBS) at room temperature. Then, cells were extensively washed with PBS supplemented with $\mathrm{CaCl}_{2}$ and $\mathrm{MgCl}_{2}$, permeabilized with $0.2 \%$ Triton-X100 and incubated for $2 \mathrm{~h}$ at room temperature with 5\% BSA in PBS. Primary and secondary antibodies were applied in 5\% bovine serum albumin (BSA) in PBS. Cells were labeled with primary antibodies overnight at $4{ }^{\circ} \mathrm{C}$. Cells were washed and then incubated with secondary antibodies for $1 \mathrm{~h}$ at room temperature. Cells were then washed in PBS and mounted on glass slides with Fluoromount mounting medium (Sigma-Aldrich). Fluorescence images were acquired by using Zeiss Confocal LSM510 system (Zeiss, Jena, Germany) with a sequential acquisition setting at $1024 \times 1024$ pixels resolution; for each image, two up to four $0.5-\mu \mathrm{m}$ sections were acquired and a $\mathrm{z}$ projection was obtained [31].

\section{Cell Culture Electrophysiology}

Whole-cell patch-clamp recordings of mEPSCs were obtained from DIV 15-16 neurons using a Multiclamp700A amplifier (Molecular Devices) and pClamp-10 software (Axon Instruments, Foster City, CA). Recordings were performed in the voltage-clamp mode. Currents were sampled at $5 \mathrm{kHz}$ and filtered at $2-5 \mathrm{kHz}$. Recording pipettes, tip resistances of 3-5 $\mathrm{M} \Omega$ were filled with the intracellular solution of the following composition (in $\mathrm{mM}$ ): 130 potassium gluconate, 10 KCl, 1 EGTA, 10 Hepes, 2 MgCl2, 4 MgATP, 0.3 Tris-GTP. At the beginning of the experiment, mEPSCs have been recorded in the external solution [Krebs' Ringer's-HEPES $(\mathrm{KRH})$ ] with the following composition (in $\mathrm{mM}$ ): $125 \mathrm{NaCl}$, $5 \mathrm{KCl}, 1.2 \mathrm{MgSO} 4,1.2 \mathrm{KH} 2 \mathrm{PO} 4,2 \mathrm{CaCl} 2,6$ glucose, 25 
HEPES-NaOH, pH 7.4 in which also TTX $(0.5 \mu \mathrm{M})$, bicuculline $(20 \mu \mathrm{M}$, Tocris, Bristol, UK), and strychnine ( $1 \mu \mathrm{M}$, Sigma-Aldrich, Milan, Italy) were included. Then, to induce chemical LTD, we applied NMDA $(20 \mu \mathrm{M})$ and glycine (20 $\mu \mathrm{M}$, Sigma-Aldrich, Milan, Italy) for $3 \mathrm{~min}$ at room temperature in $\mathrm{Mg}^{2+}$-free KRH containing TTX $(0.5 \mu \mathrm{M})$, bicuculline $(20 \mu \mathrm{M})$, and strychnine $(1 \mu \mathrm{M})$. Thirty minutes after this treatment, mEPSCs have been collected again in the starting KRH solution. Synaptic depression has been also induced in cultures by $30 \mathrm{~min}$ of $\mathrm{oA} \beta_{1-42}(500 \mathrm{nM})$ in $\mathrm{Mg}^{2+}$ free KRH containing only TTX $(0.5 \mu \mathrm{M})$, bicuculline $(20 \mu \mathrm{M})$ and strychnine; at the end of this treatment, mEPSCs have been recorded in normal KRH and analyzed. Off-line analysis of miniature events was performed by the use of Clampfit- pClamp-10 software.

\section{Data Quantification and Statistical Analysis}

Quantification of Western Blot analysis was performed by means of computer-assisted imaging (Image Lab, Biorad). The levels of the proteins were expressed as relative optical density (OD) measurements and normalized on tubulin. Values are expressed as mean \pm S.E.M. of at least three independent experiments.

Co-localization analysis was performed using Zeiss AIM 4.2 software and spines analysis was performed with ImageJ software (National Institute of Health, Bethesda, MD, USA). For co-localization, and morphological analysis, cells were chosen randomly for quantification from 4 different coverslips (2-3 independent experiments), images were acquired using the same settings/exposure times, and at least 10 cells for each condition were analyzed. Statistical evaluations were performed by using 2-tailed Student's $t$ test (a $p$ value less than 0.05 was considered significant) or, when appropriate, by using one-way ANOVA followed by Bonferroni's post hoc test or Kruskal-Wallis analysis of variance followed by Dunn's post hoc test.

Acknowledgements We thank A. Longhi and E. Zianni for technical assistance. Acknowledgement is made to the donors of the Alzheimer Disease Research, a program of the BrightFocus Foundation, for supporting EM.

Authors' Contributions SM, EM, LV, and SP carried out and analyzed the biochemical and confocal imaging experiments. NS performed TEM study. FA carried out electrophysiological experiments and their analysis. $\mathrm{EM}, \mathrm{SM}$, and MDL conceived the study and wrote the manuscript. FG and FA contributed to the writing. All authors read and approved the final manuscript.

Funding information This project has received funding from the European Union's Horizon 2020 research and innovation program under the Marie Skłodowska-Curie grant agreement No 676144 (Synaptic Dysfunction in Alzheimer Disease, SyDAD) to MDL, from the Italian Ministry of University and Research (PRIN 2015N4FKJ4 to MDL, FFABR to EM, MIUR Progetto Eccellenza), from AIRAlzh Onlus-
COOP Italia (fellowship to SP), from the Veronesi Foundation Young Investigator Research Programme 2013 (to EM), from the Alzheimer's Association (NIRP-14-304969, to EM), from an Alzheimer Disease Research program research fellowship of BrightFocus Foundation (A2014314F, to EM), from an intramural grant of University of Milan to EM (Fondo di sviluppo unimi- linea2 - PSR2017_DIP_022_03), from an intramural grant of University of Milan to FA ("Piano di Sostegno alla Ricerca, Linea 2 - Progetto giovani ricercatori”, BIOMETRA Department). This work was supported by MIUR - PON "Ricerca e Innovazione" PerMedNet id project ARS01_01226.

\section{Compliance with ethical standards}

The Institutional Animal Care and Use Committee of University of Milan and the Italian Ministry of Health (\#326/2015) approved all the experiments involving primary neuronal cultures preparation.

Open Access This article is distributed under the terms of the Creative Commons Attribution 4.0 International License (http:// creativecommons.org/licenses/by/4.0/), which permits unrestricted use, distribution, and reproduction in any medium, provided you give appropriate credit to the original author(s) and the source, provide a link to the Creative Commons license, and indicate if changes were made.

\section{References}

1. DeKosky ST, Scheff SW (1990) Synapse loss in frontal cortex biopsies in Alzheimer's disease: correlation with cognitive severity. Ann Neurol 27:457-464. https://doi.org/10.1002/ana.410270502

2. Klein WL, Krafft GA, Finch CE (2001) Targeting small Abeta oligomers: the solution to an Alzheimer's disease conundrum? Trends Neurosci 24:219-224

3. Hardy J, Selkoe DJ (2002) The amyloid hypothesis of Alzheimer's disease: progress and problems on the road to therapeutics. Science 297:353-356. https://doi.org/10.1126/science.1072994

4. Pliássova A, Lopes JP, Lemos C, Oliveira CR, Cunha RA, Agostinho $\mathrm{P}$ (2016) The association of amyloid- $\beta$ protein precursor with $\alpha$ - and $\beta$-secretases in mouse cerebral cortex synapses is altered in early Alzheimer's disease. Mol Neurobiol 53:5710-5721. https://doi.org/10.1007/s12035-015-9491-9

5. (1993) Cellular processing of beta-amyloid precursor protein and the genesis of amyloid beta-peptide. 75:1039-1042.

6. Jorissen E, Prox J, Bernreuther C, Weber S, Schwanbeck R, Serneels L, Snellinx A, Craessaerts K et al (2010) The disintegrin/metalloproteinase ADAM10 is essential for the establishment of the brain cortex. J Neurosci 30:4833-4844. https://doi. org/10.1523/JNEUROSCI.5221-09.2010

7. Kuhn P-H, Wang H, Dislich B, Colombo A, Zeitschel U, Ellwart JW, Kremmer E, Roßner S et al (2010) ADAM10 is the physiologically relevant, constitutive alpha-secretase of the amyloid precursor protein in primary neurons. EMBO J 29:3020-3032. https://doi. org/10.1038/emboj.2010.167

8. Kamenetz F, Tomita T, Hsieh H, Seabrook G, Borchelt D, Iwatsubo T, Sisodia S, Malinow R (2003) APP processing and synaptic function. Neuron 37:925-937

9. Cirrito JR, Yamada KA, Finn MB, Sloviter RS, Bales KR, May PC, Schoepp DD, Paul SM et al (2005) Synaptic activity regulates interstitial fluid amyloid-beta levels in vivo. Neuron 48:913-922. https://doi.org/10.1016/j.neuron.2005.10.028

10. Marcello E, Saraceno C, Musardo S, Vara H, de la Fuente AG, Pelucchi S, di Marino D, Borroni B et al (2013) Endocytosis of 
synaptic ADAM10 in neuronal plasticity and Alzheimer's disease. J Clin Invest 123:2523-2538. https://doi.org/10.1172/JCI65401

11. Hsieh H, Boehm J, Sato C, Iwatsubo T, Tomita T, Sisodia S, Malinow R (2006) AMPAR removal underlies Abeta-induced synaptic depression and dendritic spine loss. Neuron 52:831-843. https://doi.org/10.1016/j.neuron.2006.10.035

12. Kim JH, Anwyl R, Suh YH, Djamgoz MBA, Rowan MJ (2001) Use-dependent effects of amyloidogenic fragments of (beta)-amyloid precursor protein on synaptic plasticity in rat hippocampus in vivo. J Neurosci 21:1327-1333

13. Li S, Hong S, Shepardson NE, Walsh DM, Shankar GM, Selkoe D (2009) Soluble oligomers of amyloid Beta protein facilitate hippocampal long-term depression by disrupting neuronal glutamate uptake. Neuron 62:788-801. https://doi.org/10.1016/j.neuron.2009. 05.012

14. Lacor PN, Buniel MC, Chang L, Fernandez SJ, Gong Y, Viola KL, Lambert MP, Velasco PT et al (2004) Synaptic targeting by Alzheimer's-related amyloid beta oligomers. J Neurosci 24: 10191-10200. https://doi.org/10.1523/JNEUROSCI.3432-04.2004

15. Lacor PN, Buniel MC, Furlow PW, Sanz Clemente A, Velasco PT, Wood M, Viola KL, Klein WL (2007) Abeta oligomer-induced aberrations in synapse composition, shape, and density provide a molecular basis for loss of connectivity in Alzheimer's disease. J Neurosci 27:796-807. https://doi.org/10.1523/JNEUROSCI.350106.2007

16. Shankar GM, Bloodgood BL, Townsend M, Walsh DM, Selkoe DJ, Sabatini BL (2007) Natural oligomers of the Alzheimer amyloidbeta protein induce reversible synapse loss by modulating an NMDA-type glutamate receptor-dependent signaling pathway. J Neurosci 27:2866-2875. https://doi.org/10.1523/JNEUROSCI. 4970-06.2007

17. Lu W, Man H, Ju W et al (2001) Activation of synaptic NMDA receptors induces membrane insertion of new AMPA receptors and LTP in cultured hippocampal neurons. Neuron 29:243-254

18. Beattie EC, Carroll RC, Yu X, Morishita W, Yasuda H, von Zastrow M, Malenka RC (2000) Regulation of AMPA receptor endocytosis by a signaling mechanism shared with LTD. Nat Neurosci 3:12911300. https://doi.org/10.1038/81823

19. He K, Lee A, Song L, Kanold PO, Lee HK (2011) AMPA receptor subunit GluR1 (GluA1) serine-845 site is involved in synaptic depression but not in spine shrinkage associated with chemical longterm depression. J Neurophysiol 105:1897-1907. https://doi.org/ 10.1152/jn.00913.2010

20. Hardingham GE, Bading H (2010) Synaptic versus extrasynaptic NMDA receptor signalling: implications for neurodegenerative disorders. Nat Publ Group 11:682-696. https://doi.org/10.1038/ nrn2911

21. Gladding CM, Raymond LA (2011) Mechanisms underlying NMDA receptor synaptic/extrasynaptic distribution and function. Mol Cell Neurosci 48:308-320. https://doi.org/10.1016/j.men. 2011.05.001

22. Kullmann DM, Lamsa KP (2007) Long-term synaptic plasticity in hippocampal interneurons. Nat Rev Neurosci 8:687-699. https:// doi.org/10.1038/nrn2207

23. Paoletti P, Bellone C, Zhou Q (2013) NMDA receptor subunit diversity: impact on receptor properties, synaptic plasticity and disease. Nat Publ Group 14:383-400. https://doi.org/10.1038/nrn3504

24. Liu L, Wong TP, Pozza MF, Lingenhoehl K, Wang Y, Sheng M, Auberson YP, Wang YT (2004) Role of NMDA receptor subtypes in governing the direction of hippocampal synaptic plasticity. Science 304:1021-1024. https://doi.org/10.1126/science.1096615

25. Lambert MP, Barlow AK, Chromy BA, Edwards C, Freed R, Liosatos M, Morgan TE, Rozovsky I et al (1998) Diffusible, nonfibrillar ligands derived from Abeta1-42 are potent central nervous system neurotoxins. Proc Natl Acad Sci U S A 95:6448-6453

26. Walsh DM, Klyubin I, Fadeeva JV, Cullen WK, Anwyl R, Wolfe MS, Rowan MJ, Selkoe DJ (2002) Naturally secreted oligomers of amyloid beta protein potently inhibit hippocampal long-term potentiation in vivo. Nature 416:535-539. https://doi.org/10.1038/ $416535 \mathrm{a}$

27. Hu N-W, Klyubin I, Anwyl R, Rowan MJ (2009) GluN2B subunitcontaining NMDA receptor antagonists prevent Abeta-mediated synaptic plasticity disruption in vivo. Proc Natl Acad Sci U S A 106:20504-20509. https://doi.org/10.1073/pnas.0908083106

28. Li S, Jin M, Koeglsperger T, Shepardson NE, Shankar GM, Selkoe DJ (2011) Soluble A $\beta$ oligomers inhibit long-term potentiation through a mechanism involving excessive activation of extrasynaptic NR2B-containing NMDA receptors. J Neurosci 31: 6627-6638. https://doi.org/10.1523/JNEUROSCI.0203-11.2011

29. Rönicke R, Mikhaylova M, Rönicke S, Meinhardt J, Schröder UH, Fändrich M, Reiser G, Kreutz MR et al (2011) Early neuronal dysfunction by amyloid $\beta$ oligomers depends on activation of NR2B-containing NMDA receptors. Neurobiol Aging 32:22192228. https://doi.org/10.1016/j.neurobiolaging.2010.01.011

30. Hick M, Herrmann U, Weyer SW, Mallm JP, Tschäpe JA, Borgers M, Mercken M, Roth FC et al (2015) Acute function of secreted amyloid precursor protein fragment APPs $\alpha$ in synaptic plasticity. Acta Neuropathol 129:21-37. https://doi.org/10.1007/s00401-0141368 -x

31. Malinverno M, Carta M, Epis R, Marcello E, Verpelli C, Cattabeni F, Sala C, Mulle C et al (2010) Synaptic localization and activity of ADAM10 regulate excitatory synapses through N-cadherin cleavage. J Neurosci 30:16343-16355. https://doi.org/10.1523/ JNEUROSCI.1984-10.2010

32. Selkoe DJ (2011) Alzheimer's disease. Cold Spring Harb Perspect Biol 3:a004457-a004457. https://doi.org/10.1101/cshperspect. a004457

33. (1991) Physical basis of cognitive alterations in Alzheimer's disease: synapse loss is the major correlate of cognitive impairment. 30:572-580. doi: https://doi.org/10.1002/ana.410300410

34. Stine WB, Dahlgren KN, Krafft GA, LaDu MJ (2003) In vitro characterization of conditions for amyloid-beta peptide oligomerization and fibrillogenesis. J Biol Chem 278:11612-11622. https:// doi.org/10.1074/jbc.M210207200

35. Marcello E, Gardoni F, Mauceri D, Romorini S, Jeromin A, Epis R, Borroni B, Cattabeni F et al (2007) Synapse-associated protein-97 mediates alpha-secretase ADAM10 trafficking and promotes its activity. J Neurosci 27:1682-1691. https://doi.org/10.1523/ JNEUROSCI.3439-06.2007

36. Boraso M, Viviani B (2011) Glia-neuron sandwich cocultures: an in vitro approach to evaluate cell-to-cell communication in neuroinflammation and neurotoxicity. Methods Mol Biol 758:135-152. https://doi.org/10.1007/978-1-61779-170-3_9

Publisher's Note Springer Nature remains neutral with regard to jurisdictional claims in published maps and institutional affiliations. 